\title{
FORMAS MODALES DE LA GNOSEOLOGÍA ÉTICA Y LA EDUCACIÓN
}

Luis Xavier Solís Sotomayor

Docente de la Carrera de Filosofía y Pedagogía de la

Universidad Politécnica Salesiana

\section{La gnoseología ética}

Los nuevos esquemas de la educación, al igual que el respeto profundo del ser humano como el fin último, nos llevan a construir nuevas costumbres y por ende a transmutar los valores para nuestra época (Cfr. Nietzsche, 2001). Iniciamos ahora un análisis sistemático de los principales componentes del aprendizaje y de la vida ética de la persona, poniendo de relieve en ello la consideración de la ayuda educativa que reciben los estudiantes.

El primero de los componentes que deberemos analizar es el componente ético, dado el papel de doble llave que desempeña en la vida ética. Así, por una parte, el conocimiento ético es la puerta de entrada en la vida moral, en el sentido de que sólo cuando una persona sabe que su decisión o su acción le compromete éticamente, es decir, que es buena o mala desde el punto de vista ético, puede decirse de ella que es moral o inmoral. Y, por otra, 
desde el punto de vista de su corrección o no, lo cual constituye un horizonte para toda actividad moral de la persona.

Ahora bien, saber qué es correcto y qué no lo es, no es algo que una persona dictamine en cada caso porque sí o porque se da como una cuestión del azar, es algo que supone unos patrones sobre qué comportamientos están bien y cuáles mal desde el punto de vista de la ética: bien sea intuitivamente, bien mediante juicios (esa persona está haciendo mal porque está robando), por razonamientos (aunque no lo parezca esa persona está robando, porque se ha quedado con algo de valor que otra persona había olvidado momentáneamente) (Cfr. Aristóteles, 1997). Por eso, para comprender adecuadamente este comportamiento de la vida moral es preciso conocer los diversos tipos en que el conocimiento ético se explicita o constituye en la persona, es decir, los patrones de juicios y los razonamientos morales, todos los cuales se relacionan intrínsecamente entre sí1. Así la opinión ética de una persona (un patrón moral) presupone con frecuencia juicios e incluso razonamientos éticos, y un razonamiento procede basándose o aplicando patrones y juicios. Veamos, pues, más en detalle los principales tipos de conocimiento ético.

\section{a) Pautas morales}

Por pautas morales entendemos aquellos conocimientos en los que se basa la persona para evaluar la corrección o incorrección moral de una actividad humana, susceptible a esa evaluación ética (como son determinados pensamientos, afectos, deseos, valores, actitudes, decisiones, opiniones, actos...). 
Estos patrones presentan, a su vez, varios tipos, según la mayor o menor firmeza y seguridad que ofrece al pensamiento o a la decisión de la persona. Así, podemos distinguir en ellos los principios más firmes y las opciones.

Los principios morales conforman la estructura básica del conocimiento ético, ya que ellos se basan únicamente en la persona, sus juicios y razonamientos éticos.

"Principio" es un término emparentado con "principal” y con "principiar". Lo primero se comprende aquí por ese carácter fundamental de los principios éticos. Lo segundo, porque "principiar" es precisamente lo que hacen estos principios éticos, en el sentido de que a partir de ellos la persona dictamina la eticidad positiva o negativa de los actos que caen en el radio de la acción del principio interpelado por el acto en cuestión.

De estos principios se pueden afirmar con carácter general que dan razón suficiente a la persona del porqué de este signo ético; así, el respeto a la vida humana es un principio moral a partir del cual la persona dictamina que cuidar a un enfermo está bien y asesinar está mal desde el punto de vista ético. Estos principios dan normalmente una razón suficientemente válida para la conducta.

Ahora bien, decir "Razón Suficiente" no es lo mismo que "Razón incuestionable, última". Así, de los principios hay unos que dan razón suficiente, pero no última sobre el comportamiento ético que principian, y hay otros que son principios últimos, en cuanto que aportan a la persona la razón última de por qué obrar de una determinada manera. Alguna persona puede preguntarse todavía: "¿y por qué hay que respetar la vida de los demás?” Cuestión que remite a un principio no sólo suficiente sino también último, es decir, a un principio que nos remite a otra idea o conocimiento posterior que le 
valide a una vez a él mismo. Esto nos lleva a responder a la pregunta planteada que la razón de respetar la vida de los demás en la exactitud o dignidad de todo ser humano, se estará recurriendo a la razón o principio último del principio (normalmente suficiente en la vida practica) de que hay que respetar la vida del otro (Cfr. Aristóteles, 1970: Principio de causalidad).

De entre todos los principios morales, los que han alcanzado un consenso más universal son: el primero, la excelsitud o dignidad intrínseca de todo ser humano, que le hace acreedor a un respeto y a un trato peculiar y superior a los demás seres del mundo y que constituye el principio ético último. Hablar de dignidad intrínseca del ser humano equivale, pues, a afirmar que reconocemos en la realidad del hombre algo peculiarmente valioso, por comparación a los demás seres que conocemos, que le hace "digno de" ese respeto y trato especial2. Los Derechos Humanos, que acompañan a esa dignidad y que concretan ese respeto y trato peculiares que merece todo individuo humano es el hecho de Ser. Y la Justicia, principio y conocimiento ético principal y básico en cuanto que, al determinar si se reconoce, da o exige a cada uno lo que le corresponde, permite discernir en cada acción o situación si se atienden o se conculcan esos derechos y, consiguientemente, si se respeta esa dignidad.

Un segundo tipo de patrones morales es el constituido por las opciones morales, ideas sobre la eticidad positiva o negativa de una actividad que no ofrece la firmeza y la seguridad de los principios.

Lo más común es que estas opiniones se originen cuando la aplicación de algún principio a casos o a situaciones concretas (sea inmediatamente a través de juicios o razonamientos) no se impone con evidencia. Por ejemplo, supuesto el principio del respeto a la vida, algu- 
nas formas de eutanasia son susceptibles a opiniones diferentes entre diversas personas, de forma que para cada una de ellas su "opinión" es la que constituye el conocimiento ético por el que se regirá moralmente.

Las opiniones pueden versar también sobre los principios mismos, sea en el plano de su fundamentación o razón de ser, sea porque no se reconoce a un principio determinado como "razón suficiente" para obrar (no convence suficientemente), sea en el plano de la comprensión o interpretación de su contenido.

Un tercer tipo de patrones morales es el constituido por determinadas opciones de la persona. Como cuando, por ejemplo, una persona opta por confiar en otras aun a riesgo de que puedan engañarla; a esa persona le parecerá que actúa bien si obra de acuerdo con esa opción y mal si no lo hace (Cfr. Kant, 2000).

\section{b) Juicios éticos}

Un segundo tipo o nivel del conocimiento ético lo constituyen los juicios éticos o morales.

Un juicio ético es una idea sobre la corrección o incorrección ética de una actividad humana (determinados pensamientos, afectos, deseos, valores, actitudes, decisiones, opciones, actos, hábitos, situaciones, circunstancias...), que forma o expresa una persona al confrontar esa actividad con algún patrón moral, por ejemplo: una persona que coteja una serie de actuaciones propias y de otros en una empresa en la que se observan irregularidades de tipo ético-económico con el principio moral que establece no robar; se forma como consecuencia de esa confrontación una serie de juicios sobre la honradez en unos casos y la falta de honradez en otros, que constituyen otros tantos juicios éticos. 


\section{c) Razonamientos éticos}

Un tercer tipo o nivel de conocimiento ético es el razonamiento en el orden moral de la existencia humana o razonamiento ético.

Si por "razonamiento" se entiende en general un conjunto de ideas concatenadas que conducen a una conclusión, por razonamiento ético entendemos lógicamente el razonamiento constituido por una serie de ideas concatenadas en las que se implican y entran en juego principios (opiniones u opciones) o juicios morales, y que conducen a una conclusión de orden moral.

Se trata, por lo tanto, de un tipo de conocimiento ético más complejo que los anteriores y que requiere, por lo mismo, una maduración y un desarrollo superior de la persona. De un tipo de conocimiento ético que, por otra parte, no es algo que la persona ejercite con la habitualidad con que se ve precisada a recurrir a los patrones morales y a los juicios éticos; el razonamiento ético es algo que más bien espera para activarse a que se dé alguna circunstancia que lo requiera; por ejemplo, una situación de duda sobre qué pensar o qué hacer, una discusión...

Finalmente, interesa reseñar aquí también con vistas al aprendizaje ético, la importancia del razonamiento compartido, entendiendo por tal razonamiento el que se ejercita en los diálogos entre varias personas, y en ciertas consultas de unas personas a otras (Rubio, 1988: 45).

Éste es un tipo de razonamiento en el que cada persona no deduce a solas y siguiendo únicamente su propio discurso; sino que procede incorporando a sus razonamientos los juicios y razones de aquéllos con quienes la persona dialoga (Buber, 1967: 147). La razón procede, pues, en estos casos "dialógicamente", es decir, avanza en su discurso a través del diálogo, se hace razón dialógica. Y el razonamiento de cada persona puede desembocar en 
una conclusión final reforzada por el consenso o iluminada por el discurso de quienes dialogan.

\section{La Justicia como principio ético}

\section{a. Hacia una gnoseología ética de la justicia}

Una vez conocidos los principales tipos de conocimiento ético, es bueno considerar más en detalle el tipo o nivel de los principios morales, en atención a su importancia crucial en el conocimiento ético y, por su medio, también para la conciencia y para la vida moral en general de la persona.

Comencemos por la consideración de la justicia, ya que constituye el principio ético principal y básico dejando para un momento posterior los derechos humanos, principios del conocimiento de los deberes éticos concretos. En cuanto a la comprensión del papel de la dignidad humana en el conocimiento ético, pues la consideración de los principios ayuda a descubrirle como el soporte y principio último de dicho conocimiento.

Pues bien, ¿qué se entiende por justicia? En su sentido no sólo más general sino también más propio: "Por justicia se entiende dar o exigir a cada uno lo que le corresponde". De tal manera que, si a toda persona le corresponde su buena fama, es de justicia que los demás respeten esa fama y no la calumnien; por ejemplo: si a un niño le corresponde recibir el cariño, los cuidados y la educación de sus padres, es de justicia que éstos le aporten; si en una transacción comercial se ha acordado el valor de lo que se intercambia, es de justicia que a la entrega por una de sus partes corresponda el otro con la entrega de la suya; si se hace una distribución de bienes de cualquier tipo, ésta será también conforme a justicia si se da a cada uno lo que le corresponde, etc. 
Es claro que la justicia presupone y se asienta sobre la igualdad básica en dignidad y derechos de todos los seres humanos. Por lo que, mientras en una distribución de alimentos entre hombres y animales, se dará preferencia a los primeros porque se considera que su dignidad es superior a la de los animales y que, por lo mismo, también sus derechos lo son; cuando la distribución es sólo entre hombres la justicia procede sobre la base de que todas las personas son iguales en dignidad, por lo que, en principio, todos tienen los mismos derechos.

Es importante tomar conciencia de que la justicia constituye el principio o conocimiento ético principal y básico, ya que aporta el criterio para evaluar en concreto la corrección o la incorrección ética intrínseca en cualquier situación o actividad humana con implicación moral.

Si una persona reconoce, atribuye, aporta, da o exige a los demás lo que corresponde a cada uno de ellos, esa persona tiene un comportamiento ético correcto. Por el contrario, en la medida en que no reconoce, atribuye, aporta, da o exige a alguien lo que le corresponde, está teniendo un comportamiento ético incorrecto, está cometiendo una falta ética.

Según esto, la justicia es la clave y la síntesis de la ética, por lo que ninguna perspectiva mejor que la de la justicia para definir a la ética.

A la ética se la suele definir por relación a la realización adecuada a las personas y a las sociedades. En cuanto disciplina filosófica, por ética puede entenderse el conocimiento humano racional y elaborado sobre la conducta más adecuada para la realización personal de uno mismo y de los demás y para la generación del bien común (Cortina, 1986: 12). Y un significado semejante tiene en cuanta el concepto de uso común; así, "ética” es el 
término o concepto con que calificamos la conducta humana más adecuada para la realización personal, para la convivencia y para el bien común.

Si nos fijamos en este segundo sentido, la ética como conducta puede entenderse y llevarse a efecto en concreto tomando como base y norte el siguiente principio "sé justo y haz lo que quieras" (Cfr. San Agustín, 1960). Porque es claro que, si una persona hace norma de su vida el reconocer, atribuir, aportar, dar o exigir a los demás lo que le corresponde, lo que vaya hacer en cada caso será lo correcto desde el punto de vista ético. Ni robará, ni matará, ni calumniará, etc., porque eso sería no reconocer y dar a los otros lo que les corresponde como personas, sería atentar contra sus derechos a su propiedad, a la vida, a la verdad...

La ética en cuanto conocimiento humano racional y elaborado sobre la conducta más adecuada a los efectos indicados, se concreta también y puede ser definida como el conocimiento de la justicia en sí misma y en las diferentes modalidades que puede adoptar según el tipo de relaciones que pueda regular (modalidades de justicia conmutativa, distributiva, social o legal) (Cfr. Singer, 1970: 47-50).

De esta forma, las definiciones de ética se llenan de su más auténtico contenido cuado se concretan en su relación a la justicia; es decir, cuando se ve en ella el conocimiento adecuado de la justicia, sea una conducta y vidas humanas acordes a la mismas.

\section{b. Modalidades de la justicia}

El conocimiento de la justicia nos conduce, pues, a la nueva, realista y concreta concepción de la ética. Una concepción que, a su vez, reconoce e integra diversas modalidades en la justicia, una realidad que deberemos 
conocer si queremos comprender adecuadamente este principio básico del conocimiento ético. ¿Cuáles son, pues, las modalidades principales de la justicia?

- Justicia Conmutativa. Ya que es la más universal al regular la eticidad de las relaciones entre personas y de las otras relaciones análogas a aquéllas (las relaciones contractuales entre una empresa y sus trabajadores, entre una empresa y sus clientes, entre empresas).

Es una moralidad que, sobre la base o presupuesto común a cualquier tipo o modalidad de justicia de la igualdad de todos los hombres, tiene como característica peculiar la reciprocidad en aquellas relaciones entre las personas en las que cabe esperar legítimamente correspondencia (Cfr. Gastaldi, 1990: 74).

- Justicia Distributiva. Es la segunda modalidad a considerar, que regula las relaciones entre los individuos de un grupo humano o entre la autoridad y los individuos en orden a una distribución equitativa de bienes, servicios y cargos.

Se trata, por tanto, de aquella modalidad de la justicia que a la hora de distribuir bienes (por ejemplo, la renta del país), servicios (educación, atención sanitaria) y cargas (como son los impuestos), ha de regular que cada persona reciba lo que le corresponde.

¿Cómo realiza la justicia distributiva esa "regulación”? En primer lugar, es obvio que, tratándose de "justicia", el punto de partida es el ya comentado "presupuesto de la igualdad", el cual lleva a establecer que, de entrada y en principio, a todas las personas que participan en la distribución les corresponde lo mismo. 
El sentir común acepta como éticamente lícito que este punto de partida puede y deberá armonizarse en su caso -en orden a reconocer, dar o exigir a cada uno lo que le corresponde verdaderamente-, atendiendo fundamentalmente a cuatro factores:

1. Los méritos objetivos, que pueden ser distintos en unas personas y otras, de forma que un mayor mérito haga plausible a una mejora en la repartición de algún bien o a un trato de favor si se refiera a la distribución de cargas.

2. Las necesidades particulares, reconocidas socialmente como merecedoras de ser tenidas en cuenta a la hora de la distribución. Ejemplo, instituir en el centro educativo un equipo de apoyo para los estudiantes con necesidades educativas especiales altera la igualdad primera (ese equipo de apoyo cuesta dinero, es necesario un especialista para su mantenimiento...), más real al modularla con esa atención a unas necesidades particulares.

3. Y, finalmente, el factor constituido por la necesaria atención al bien común en la distribución. Por ejemplo, no va contra el derecho de todas las personas a la educación y a la preparación profesional que en el acceso a determinadas carreras se examine la actitud del candidato para las mismas, ni tampoco que se limite el número de plazas en consideración a las necesidades de la sociedad y a la plaza laboral.

- Justicia social. Se propone como forma modal también la "justicia social”, aun cuando muchos consideran innecesario hablar de ella porque no 
aporta algo nuevo y distinto de lo que significa una "justicia distributiva", llevada hasta sus últimas consecuencias ${ }^{3}$.

Se entiende por justicia social "la justicia aplicada al ámbito de los derechos humanos sociales de los ciudadanos. Es decir, la justicia aplicada a los aquellos derechos humanos de cada hombre y mujer, que interpelan y comprometen a la sociedad de la que forman parte, para que ésta salga garante de su ejercicio"; son hoy por hoy derechos humanos reconocidos generalmente como "sociales": el derecho al trabajo, a la educación, a la atención sanitaria, a la vivienda, a un buen trato, a la libertad de expresarse... Y consiguientemente, los individuos se sienten justificados para esperar de la sociedad la defensa o la ayuda que precisan para ejercitarlos, y la sociedad se reconoce obligada a buscar las soluciones necesarias para que ellos sean ejercidos por todos los ciudadanos con toda la realidad que ellos acarrean.

Esto nos lleva a un cuestionamiento: ¿qué peculiaridades presenta esta moralidad de justicia por comparación a las otras dos anteriores?

La primera peculiaridad y el factor fundamental en juego en la práctica de la justicia social, es el papel explícito de la dignidad de cada ser humano. En la justicia conmutativa y la distributiva, la conciencia de la dignidad del ser humano no es algo que aflore necesariamente en cada acto en el que se han de practicar; de tal manera que, en una transacción de bienes (objeto de la justicia conmutativa) la argumentación para proceder con justicia recurrirá a la igualdad entre las personas, a la reciprocidad y a la equidad, e igualmente se recurre a la argumentación de igualdad en un reparto de bienes o cargas. En la justicia social, en cambio, este razonamiento se basa directa- 
mente en la dignidad humana, en el hecho fundamental y ontológico de la existencia del ser, que fundamenta y da origen a los derechos sociales de la persona, ya que el ser aparece como un fenómeno que irrumpe o desgarra el velo de la nada (Cfr. Leibniz, 1984). De esta manera el discurso que plantea la justicia social es: "todo ser humano tiene derecho, por el hecho de SER persona a llevar una vida digna", lo que implica los derechos para su propia realización como SER existente". Un factor que, obviamente y como en las otras modalidades de la justicia, es acompañado ya por el punto de partida o por el "presupuesto de la igualdad" entre todos los hombres. Por lo que, la praxis de la justicia social partirá de la idea de que, en principio, todos los hombres tienen igual derecho a ejercitar y a ver satisfechos sus derechos sociales y, consiguientemente, tienen también los mismos derechos a que la sociedad sea garante de que los ejerciten o puedan ejercitarlos.

La afirmación de que la sociedad ha de ser garante de estos derechos pone de manifiesto un nuevo factor y una segunda peculiaridad de la justicia social: la responsabilidad de la sociedad, porque todos los ciudadanos puedan llevar una vida digna de seres humanos, con todo lo que ello implica de respeto, defensa y apoyo eficaz en su caso al ejercicio de los derechos sin el cual esa vida digna no es posible.

Es cierto que la sociedad tiene también responsabilidades en la práctica de la justicia conmutativa y de la justicia distributiva; ahora bien, la responsabilidad que tiene en estas modalidades de la justicia no alcanza unas cotas de protagonismo equiparables al de la responsabilidad que crea en la sociedad la justicia social. En la modalidad de la justicia conmutativa la sociedad ejercita su responsabilidad principalmente legislando al respecto y apli- 
cando y haciendo ejecutar las disposiciones de la "justicia legal"; en la modalidad de la justicia distributiva la ejercita también por esos mismos caminos, a los que puede añadir mecanismos de intervención que garanticen la equidad en la distribución de los bienes, servicios y cargas; y en la modalidad de la justicia social, la sociedad además de ejercitar su responsabilidad por los caminos anteriores ha de ejercerla arbitrando los medios necesarios para que nadie se quede sin poder ejercer sus derechos sociales, algo que puede reclamar intervenciones especiales y que pone de manifiesto otros dos nuevos factores peculiares de la justicia social.

1.- La modulación de que la atención a las necesidades de todos los ciudadanos basadas en sus derechos sociales debe llegar a todos los miembros de la sociedad sin exclusión.

Un factor reclamado por el hecho de que la sociedad no debe permitir que queden excluidos de la distribución de bienes y servicios determinados sectores de población descolgados sin culpa suya del progreso o sencillamente de ese bien escaso que es el trabajo (parados, determinados grupos étnicos, deficientes, ancianos, inmigrantes...), aun cuando esas personas y grupos no puedan cotizar en impuestos o aportar de otra forma al bien común (¡qué más querrían muchos de ellos que poder aportar!).

2.- La modulación de que esta atención debe alcanzar al menos los listones mínimos que pide la dignidad humana.

Una sociedad no debe darse por satisfecha con el hecho de que nadie se muera de hambre en ella, una sociedad solidaria aspirará además a que todos los ciudadanos participen también en 
la distribución de otros bienes necesarios para la vida humana digna. Es una participación del ser humano en todas las dimensiones (sociales, políticas, económicas, culturales, estéticas, sicológicas, religiosas).

Estas modalidades o modulaciones necesarias para la práctica de la justicia social desbordan los límites de las otras justicias mencionadas, ya que supone acciones como la de prestar servicios a personas que no aportan a la sociedad correspondiente o la de dejar de prestárselos quizá a algunos que aportan y que pueden además pagárselos privadamente para poder atender a aquéllos si los fondos públicos son pocos. Acciones que, evidentemente, sólo son posibles si la sociedad integra en su proceder la práctica de la solidaridad. Por consiguiente, la solidaridad constituye también un factor y una peculiaridad de la modalidad justicia social.

En realidad, la justicia social también distribuye bienes, servicios y cargas: los correspondientes a los derechos sociales de los ciudadanos. Lo que sucede es que, al hacerlo, rompe -de la mano de la toma de conciencia del derecho de todo ser humano a llevar una vida digna y de la mano de la solidaridad- lo que la justicia distributiva aplicada a la letra puede tener de sostén para determinadas cuestiones sociales, llevando la protección y la ayuda social a todos los ciudadanos sin excepción y hasta unos niveles que merezcan el calificativo de humanos.

- Justicia legal. Es una modalidad análoga a las consideradas hasta el momento, en cuanto no aporta contenidos intrínsecos nuevos. 
Así, por justicia legal se entiende aquella modalidad de la justicia cuyo objetivo es la regulación legal de los imperativos de la justicia conmutativa, distributiva y social en todos los órdenes en que éstas pueden ejercitarse con efectos explícitos o potencialmente públicos.

\section{Los derechos humanos como fundamento snoseológico de la ética}

\section{a. Noción de derecho humano}

- Responsabilidad gnoseológica-ética de los Derechos Humanos. El concepto de "derecho humano" es complejo y muy difícil de precisar y resumir en sus rasgos fundamentales, tomado en cuenta su verdadera importancia, no hay algo definitivo en los más experimentados estudios, para captar su verdadera objetividad. Esto es lo que nos lleva a tomar una posición de responsabilidad gnoseológica de su concepto.

Para penetrar en su significado seguiremos el camino de la profundización, al encontrarnos con un verdadero nominalismo y el valor y significado de los términos empleados en la expresión "derechos humanos", porque un uso tan universal de los mismos no pueden menos de responder a una intuición compartida y que se ha volcado en ellos, por lo que si captamos esta institución, podemos hacer un buen camino para la comprensión de los aspectos fundamentales del concepto.

La intuición compartida y presente en el segundo término de la expresión, "humanos", parece que no 
puede ser otra que la afirmación de que se trata de algo propio del hombre, de algo "específicamente humano" y, propio de todos y cada uno de los hombres.

En lo que respecta al empleo del término "derechos", la intuición que se expresa lógicamente por su medio es que se reconoce un estatuto jurídico del derecho a aquello que se afirma; es decir, que se considera que los contenidos de los derechos humanos son facultades que tiene el hombre para realizar, no realizar o exigir algo, pues esto es lo que significa propiamente el término "derecho"4.

Esta primera aproximación nos permite, pues, concluir que por derechos humanos se entiende: determinadas facultades propias del ser humano, que le capacitan para hacer o no hacer algo o para exigir algo a otros en función de su propia realización.

- Los derechos humanos como postulados de la razón práctica. Esto nos lleva a plantear las preguntas: ¿Quién determina los derechos humanos y en qué se basa para hacerlo? Veamos la respuesta a partir de un ejemplo: los "derechos de los animales".

Pues bien, en un animal (un perro o un caballo...) admiramos su vida, su movilidad, su belleza, su fidelidad al hombre, su simpatía ("no le falta más que hablar" llegamos a decir de algunos), y éstas y otras percepciones de la realidad de los animales nos conducen a reconocer unos derechos en los animales, algo propio de ellos (no los reconocemos, así en las plantas o las piedras). Así, tienen derecho a que no se les haga sufrir, a recibir el alimento que precisan, etc., y los hombres reconocemos ese derecho y nos sentimos interpelados y com- 
prometidos por él: no debes hacer sufrir a los animales sin necesidad, debemos procurarle sustento...

Los derechos de los animales son algo que el hombre determina a partir de un conocimiento y valoración de la realidad de los animales, y por lo que el mismo hombre siente el compromiso de que debe respetarlos.

Este ejemplo nos ayuda a comprender el reconocimiento por el hombre de los derechos del mismo hombre, pues el proceso es similar. Vemos un niño, y su realidad (su inteligencia, su curiosidad, su afectividad, etc.) nos admira y nos hace comprender que precisa cuidados, afecto, educación, que tiene derecho a ello. Y es así como afirmamos unos derechos del niño, algo que nos interpela y por lo que nos sentimos comprometidos: debemos cuidar a ése y a todos los niños, alimentarles darles afecto, educación. O vemos a un adulto, a cualquier persona, y nos admiran su inteligencia, su capacidad de amar, su lenguaje, realidades propias y específicas del ser humano, y comprendemos que debe poder hacer lo que es acorde a esas realidades y no hacer lo contrario, y que debe poder exigir que los demás hombres respeten ese poder hacer o no hacer o respondan ayudándole en su exigencia fundada de ayuda para poder realizarlas. Y, a partir de ahí, reconocemos y afirmamos sus derechos humanos, pues nos sentimos interpelados por ese respeto y obligados a aportar esa ayuda que precisa.

Un "derecho humano" es, pues, algo que el hombre determina a partir de aspectos y dimensiones de la realidad humana que valora especialmente y que considera propio del hombre y sólo de él, y por lo que se siente comprometido sea a respetarlo, sea a ayudar a su realización.

Esta concepción implica algo que no debemos pasar por alto, pues significa otra importante perspectiva 
sobre los derechos humanos: la afirmación de que ellos son algo que el hombre reconoce y valora en el mismo hombre. No son algo que el conjunto de los hombres acuerda establecer discrecionalmente para poder convivir, como algunas disposiciones positivas.

El hombre no se inventa los derechos humanos: su afirmación es consecuencia de un proceso en el que el hombre percibe la realidad de la persona humana, reconoce en ella algo peculiar y específico, y valora esto en una forma especial. Los derechos humanos son un veredicto del hombre sobre el hombre, un veredicto angustiado de valoración positiva sobre sí mismo.

Por eso, no tiene nada de extraño que el reconocimiento de los derechos humanos aparezca vinculado, en los momentos más relevantes de su historia, con el de la afirmación de la "dignidad de la persona humana", y es que, lo que por un lado es contemplado como merecedor de respeto y apoyo, por otro, es visto como constituyendo la "excelsitud humana en sí misma". El preámbulo de la Declaración Universal de Derechos Humanos comienza diciendo: "Considerando que la libertad, la justicia y la paz, en el mundo tienen por base, el reconocimiento de la dignidad intrínseca y de los derechos iguales e inalienables de todos los miembros de la familia humana”. E igualmente vincula ambos conceptos el Artículo 1 de la misma declaración ${ }^{5}$.

- Los derechos humanos como principios para el comportamiento ético individual y colectivo. Otro aspecto explicitado ya, y que tampoco debe pasar desapercibido es que, al interpelar los derechos de cada persona al respeto y/o a la ayuda de los demás, el reconocimiento de los derechos humanos conforma de hecho un campo de juego de derechos (facultades para 
hacer, no hacer o exigir algo) y deberes mutuos (el deber del respeto a los derechos de los demás y de la ayuda que deba prestarse a otros para que puedan ejercerlos) entrecruzados.

Toda persona es según esto no sólo sujeto de derechos, sino también de deberes, por lo que el conjunto de relaciones que se establecen entre los hombres en base a ellos pertenece al orden de la moral, se adentra en el orden ético de la existencia humana. Por lo que, el conjunto de derechos humanos reconocidos ya conforma una red que cubre explícita o virtualmente todo el ámbito de las relaciones en este orden de la existencia humana.

Por otra parte, esta pertenencia al orden ético se comprende en su sentido más fundamental cuando se considera que reconocer, respetar y ayudar positivamente en su caso al ejercicio de los derechos humanos de otro u otros y exigir que sean tratados igualmente los propios, no es otra cosa que dar o exigir a cada uno lo que le corresponde, es decir, ejercita la justicia en el tema concreto significado por el derecho en cuestión. Por consiguiente, cada derecho humano juega legítimamente el papel de principio concreto del conocimiento y para el comportamiento ético.

Así, es reconocido hoy universalmente, como lo prueba el recurso de los derechos humanos para fundamentar las denuncias morales de determinadas conductas y situaciones, y también el que sean adoptados cada vez más como principios consensuables para la formación y el comportamiento éticos. De hecho, el respeto y el apoyo al ejercicio de los derechos humanos han pasado a erigirse cada vez más en principios de moralidad, es decir, en criterios para juzgar las conductas éticas individuales o 
sociales y la ética de las relaciones entre individuos, entre individuos e instituciones, entre instituciones entre sí, entre Estados.

\section{b. Una toma de conciencia actual sobre los derechos \\ humanos}

El reconocimiento de los derechos humanos por la humanidad es un suceso histórico que ha tenido una gestación lenta (las primeras declaraciones con pretensión a aplicación universal datan de finales del siglo XVIII), que no puede ser considerado como terminado y que probablemente durará tanto como la misma historia humana.

Aunque los derechos humanos más fundamentales han sido ya consensuados y proclamados en la familia humana, nuevas situaciones históricas o una superior madurez y evolución humana dan pie a que se reconozcan más derechos. Por ejemplo, los derechos a vivir en un mundo ecológico, el respeto a la naturaleza, a vivir en paz, a la identidad cultural, a la solidaridad de los demás y otros varios o han sido reconocidos muy recientemente, $\mathrm{o}$ están todavía en período de búsqueda de consenso.

En nuestro tiempo y a escala mundial, el punto de referencia básico sobre derechos humanos ya reconocidos y consensuados universalmente lo constituye la Declaración Universal de Derechos Humanos proclamado por la Organización de la Naciones Unidas en 1948, que consta de un preámbulo y 30 artículos (con cincuenta cláusulas en total). 


\section{La Educación: lugar del conocimiento ético}

\section{a. Educación en los principios éticos}

- El aprendizaje de los principios éticos. Es necesario recordar que en el aprendizaje básico de los principios éticos participan, como es lógico, las tres fuentes del aprendizaje: la fuente autónoma, la sociónoma y la heterónoma ${ }^{6}$.

La fuente autónoma juega un papel principal en lo que respecta al aprendizaje, por lo que es necesario tener en cuenta que el aprendizaje de los derechos humanos, como principios éticos, es más laborioso y requiere por lo general un mayor apoyo "heterónomo" que el de la justicia. La razón es que el aprendizaje de estos derechos sólo es completo en cuanto principio del conocimiento ético, cuando va acompañado del aprendizaje de esos mismos derechos como deberes, esto es algo que el niño y el adolescente no aprenden autónomamente con tanta facilidad, mientras en el aprendizaje de la justicia ésta es captada por lo general como justicia para todos y no sólo para uno mismo, en el aprendizaje de los derechos se captan fácilmente los derechos propios, pero no con tanta facilidad los derechos de los demás y los deberes propios consiguientes a aquellos. El aprendizaje autónomo de los derechos humanos y de los deberes correspondientes a ellos será mayor o menor durante éstos y los siguientes años según sea el desarrollo moral y las cualidades del adolescente y del joven; si se ha desarrollado en él un sentido de justicia fuerte, su capacitación de los derechos humanos será mayor, como será mayor su intuición de los mismos; se irá convirtiendo en una persona que es capaz de admirarse de lo humano y de sentirse interpelada por ello, y tendrá una comprensión de la aplicación de la justicia a aspectos concretos de la vida. 
En cuanto a la fuente sociónoma, ejerce por relación a este aprendizaje una doble e importante función subsidiaria y de refuerzo (Cfr. Piaget, 1977: 109-162). Ejerce la función subsidiaria de despertar o calificar en el niño, tanto el principio del conocimiento ético principal y básico la justicia, como otros principios de conocimiento ético concreto (los derechos humanos), mediante la interacción social con otros niños que ya los tienen alumbrados o a través de experiencias que provocan la conciencia de ellos por varios niños a la vez. Y ejerce una función de refuerzo en cuanto que el grupo sanciona positivamente el cumplimiento o la conculcación de estos principios como hemos demostrado en las formas modales de la justicia conmutativa, o frente a docentes con conductas acordes o desacordes con la justicia distributiva.

Una subsidiariedad y un refuerzo que, por otra parte, incrementa su importancia en la medida en que aumenta el valor del grupo en la vida social del niño y en el conjunto de sus intereses vitales. La función de refuerzo adquiere peculiar relevancia durante los años de la adolescencia, cuando el chico y la chica son particularmente receptivos al influjo de sus compañeros como parte del mecanismo de autoafirmación personal.

- Ayuda Educativa a este aprendizaje. En cuanto a la aportación de la fuente heterónoma al aprendizaje de los principios éticos (padres, docentes, hermanos, amigos...), su función es la de apoyar educativamente al aprendizaje autónomo y sociónomo de tales principios morales. Un apoyo y subsidiariedad que parece particularmente importante en lo que se refiere al reconocimiento de los deberes de uno mismo ante los derechos de los demás. 
En realidad, los educadores debemos estar prevenidos para no caer en la práctica de una indoctrinación (deformación de la subsidiariedad) que siempre entraña defectos negativos. Una inculcación heterónoma de los principios éticos puede ocasionar el rechazo de éstos, particularmente durante la adolescencia; o puede dar origen, por el contrario, a una aceptación despersonalizada de aquéllos con pérdida de autonomía moral, es decir, de la capacidad de la persona para proceder desde sí misma, desde su propio pensamiento y decisión en su vida ética.

\section{b. Educación de los juicios y razonamientos éticos}

- Necesidad de autoafirmación. Es la necesidad de la comprensión propia del mundo, actitudes de oposición y de ruptura, talante discutidor y razonador.

- Aptitudes de la inteligencia del adolescente y del joven que puedan determinarse por su mayor o menor capacidad para: a) captar los temas y problemas más importantes y saber valorar la importancia objetiva de cada uno de ellos. b) Una mayor o menor universalidad en la cantidad y variedad de temas que suscitan su interés y a los que puede aplicar estas capacidades. c) Detectar aspectos a tener presentes en el afrontamiento intelectual o práctico de un problema y para interrelacionarlos entre sí. d) Intuir o deducir las causas o razones profundas que explican o hacen entender otros niveles más visibles de la realidad.

- Con el momento de su desarrollo moral: a) Con el desarrollo de sentido ético y particular del sentido de justicia. b) Con su aprendizaje de los principios éticos. c) Con la importancia que va 
adquiriendo en su vida la conciencia moral. d) Con su sensibilidad para la solidaridad. e) Con la conformación de valores y actitudes que puedan infundir o condicionar el conocimiento ético.

\section{Conclusión:}

Todo aquello que hemos encarnado en nuestra investigación supone, en fin una exacta y clara formación del conocimiento ético en el acto educativo y del carácter de su aprendizaje en el proceso de una Epistemología de la moral, por lo que el deber, la justicia y los derechos han de aparecer permanentemente como una meta buscada e interiorizada en las diferentes corrientes del pensamiento filosófico. La relación del maestro con el educando debe ser como decía Goethe, en su obra Guillermo Meister: "cuando tomamos a los hombres como son, los hacemos peores de lo que son; cuando los tratamos como si fuesen lo que deberían ser, los ponemos en camino de llegar a ser lo que deben ser".

Un último aspecto que debemos apuntar es la relación que, en efecto, ha existido siempre entre educación y filosofía y el interés de todos los pensadores, en ese problema crucial de la educación y la formación de la persona humana; queramos o no, e incluso su formación directiva hacia una gnoseología ética expresada en la voluntad por parte de sus formuladores, la cual hace que la filosofía sea vivida, y no una mera forma de mirar los hechos, como simples espectadores. Pues la educación es el medio de la socialización y de la comunicación como: la científica, la cibernética, la informativa, la estética, y la ética, entre otras. Pues el mundo de la educación es particularmente sensible a las temperaturas sociales. 


\section{Notas}

1 Ya Aristóteles divide esta forma de conocer como virtudes ética y dianoéticas que son parte del obrar en un todo con el ser humano.

2 Las alternativas más importantes en este principio último son las positivistas (por ejemplo, hay que respetar la vida de los demás porque, si no lo hacemos, la convivencia es imposible) y la religio$s a$. En este segundo tipo el principio último puede ser positivo (un mandato de la religión de que se trate), antropológico religioso o mixto. Ejemplo de esto último lo ofrece el cristianismo, según el cual el respeto a la vida de los demás viene exigido por la dignidad natural única del ser humano (motivo antropológico), porque esa dignidad ha sido incrementada por el plan religioso de Dios (la excelsitud y dignidad de un ser amado por Dios como hijo, escogido para vivir eternamente con él), y es además un mandato divino.

3 Poner a la justicia social como otro punto exige que se corrija las escandalosas desigualdades sociales y que hacen inviable la paz entre los pueblos, dando lugar a las revoluciones explosivas de la desesperación. Es la toma de conciencia y una actitud crítica sobre la realidad social las que llevan a formular proyectos y actuaciones en formas morales, que no deben interpretarse en principio como posturas de rechazo o de enemistad, ya que ellos buscan que se salvaguarde la integridad y la dignidad de los seres humanos como fin último de toda ética. Lo expresa así el Magisterio de la Iglesia Dezinger en su edición Herder de 1990, en las encíclicas sociales desde León XIII hasta Juan Pablo II.

4 Ludwing Wittgenstein elaboró, a partir de una crítica de la lógica, las correlaciones entre los objetos y la realidad, así como también la relación entre los juicios como funciones de la verdad, que lo condujo finalmente a ocuparse de la problemática lingüística, sobre afirmaciones concretas, o sea derivaciones lógicas de los hechos, "la lógica nunca nos dice nada sobre la realidad, porque nunca la puedes captar, su naturaleza es del todo tautológica es decir se limita a expresar algo ya definido aunque de un modo distinto" (1921: 156).

5 Cf. DECLARACIÓN UNIVERSAL DE DERECHOS HUMANOS. Proclamado por la ONU el 10 de Diciembre de 1948.

6 Emmanuel Kant, en su Crítica a la razón Pura, menciona una estructura de las fuentes del conocimiento, partiendo desde los a priori y llegando a los a posteriori, y éstos formando los juicios sintéticos y analíticos de las realidades. Esto es lo que hace que el conocimiento se vuelva autónomo y crítico. 


\section{Bibliografía}

ARISTÓTELES

1970 Metafísca, Madrid: BAC.

1997 Ética a Nicómaco. Madrid: BAC.

AUTORES VARIOS

1985 Los Fundamentos Filosóficos de los Derechos Humanos. Barcelona: Serbal/UNESCO.

BUBER, Marin

1967 Yo y Tú. Buenos Aires: Buena Unión.

BUXARRAIS, María

1994 Lectura Sobre Ética. Barcelona: Universidad.

CAMPS, Vinicio

1993 Los Valores de la Educación. Madrid: Alauda.

CARDONA, César

1990 Ética del Quehacer Educativo. Madrid: Riala.

CORTINA, Adela

1986 Ética Mínima, Introducción a la Filosofía Práctica.

Madrid: Tecno

1999 Magisterio de la Iglesia. Documentos principales.

GASTALDI, Ítalo

Barcelona: Herder.

1990 El Hombre un Misterio. Aproximaciones Filosóficas Teológicas. Quito: Ediciones Don Bosco.

GOETHE, Wolfgang

1978 Guillermo Meister. Madrid: Mediterráneo.

KANT, Emmanuel

2000 Crítica a la Razón Práctica. Madrid: Libsca.

LEIBNIZ, Guillermo

1967 Ensayo de Teodicea sobre la Bondad de Dios, la Libertad NIETZSCHE, Federico del Hombre y el Origen del Mal. Madrid: BAC.

2001 El Anticristo. Madrid: Libsca.

PIAGET, Jean

1977 Epistemología Genética y Equilibración. Madrid:

RUBIO, José Fundamentos.

1988 El Hombre y la Ética. Barcelona: Paidos.

SAN AGUSTÍN

1960 Confesiones. Madrid: BAC. 
SINGEP, Pedro

1994 Ética Práctica. Barcelona: Ariel.

WITTGENSTEIN, Ludwig

1921 Tratado Lógico-Filosófico. Viena: Mostotes.

38 